\title{
Ensino técnico de nível médio: momentos de prestígio e de esquecimento se alternando durante a história da educação profissional no Brasil
}

\author{
Aline Graciele Mendonça*
}

\begin{abstract}
Resumo
Baseado em um recorte da pesquisa desenvolvida no programa de mestrado em educação apresentado à Universidade Estadual de Londrina pela autora deste trabalho, o estudo teórico teve como foco apresentar a historicidade da educação profissional abordando o ensino técnico de nível médio. Buscou-se responder ao seguinte problema: Como se constituiu ao longo dos tempos a educação profissional de nível médio? O objetivo foi fazer um resgate histórico do ensino técnico de nível médio no decorrer da história da educação profissional. Trata-se de um estudo bibliográfico, desenvolvido no modelo descritivo com base principalmente em Cunha (2005, 2000), Manfredi (2002) e Santos (2011). Evidenciou-se que a história do ensino técnico de nível médio foi marcada por momentos de valorização e de desvalorização produzidos conforme o momento político/econômico que o país apresentava, com políticas públicas fragmentadas movidas pelos interesses capitalistas.
\end{abstract}

Palavras-chave: História da Educação; Educação Profissional; Ensino técnico.

\section{Middle level of technical education: the prestigious and oblivion for switching during the history of vocational education in Brazil}

\begin{abstract}
Based on part of a research conducted in the master's program in education presented to the State University of Londrina by the author of this work, the theoretical study focused on presenting the historicity of professional education covering the mid-level technical education. We sought to answer the following problem: How constituted over time vocational high school education? The goal was a historical survey of mid-level technical education throughout the history of vocational education. This is a bibliographic study over the descriptive model based mainly in Cunha (2005 , 2000), Manfredi (2002) and Santos (2011). It was evident that the history of mid-level technical education was marked by moments of appreciation and devaluation produced as political / economic times that the country had, with piecemeal policies driven by capitalist interests .

Key words: History of Education; Vocational Education; Technical education.
\end{abstract}

\section{Introdução}

O presente estudo é um recorte de uma pesquisa que resultou na dissertação apresentada pela autora ao programa de mestrado em educação da Universidade Estadual de Londrina. Trata-se de um estudo bibliográfico, para aprofundar conhecimentos sobre a história do ensino técnico de nível médio. De acordo com Severino (2000), este estudo é utilizado para explicar um problema com base em referências teóricas publicadas em documentos, tendo a finalidade de conhecer e analisar as contribuições culturais ou científicas do passado existentes sobre um determinado assunto, tema ou problema. Recuperamos informações disponíveis e atuais, referentes ao assunto, pela consulta de livros, revistas, artigos científicos, periódicos, leis federais, internet, entre outros.

A educação profissional, ao longo da história da educação brasileira, sofreu muitas transformações desde seu início no Brasil Colônia, com as Corporações de Ofícios, até os dias atuais quando regulamentada pela Lei 9394, de 20 de dezembro de 1996. Esta Lei define em seu artigo 39, alterado pela Lei $\mathrm{n}^{\mathrm{o}} 11.741$, de 2008, que "a educação profissional e tecnológica, no cumprimento dos objetivos da educação nacional, integra-se aos diferentes níveis e modalidades de educação e às dimensões do trabalho, da ciência e da tecnologia" (BRASIL, 2008b). No $2^{\circ}$ parágrafo, a Lei cita os cursos abrangidos pela educação profissional e, no inciso II, trata "de educação profissional técnica de nível médio" (BRASIL, 1996). É nesse contexto que a pesquisa se desenvolveu, tendo como campo a educação profissional na educação básica de nível médio, em cursos técnicos oferecidos na modalidade sequencial/concomitante ao ensino médio regular.

Ao compararmos os dados das Sinopses Estatísticas da Educação Básica dos anos 2006 e 2011 - INEP (BRASIL, 2011), percebemos que houve uma diminuição no número de matrículas no

* Endereço eletrônico: aline.g.a@ @otmail.com 
ensino médio de 5,7\%, que totaliza 506.131 alunos a menos nessa modalidade de ensino. Já no ensino Técnico de nível médio o percentual de alunos matriculados entre os referidos anos aumentou 33\%, de 744.690 matrículas em 2006 passaram a 993.187 em 2011. Os dados refletem a crise do ensino médio, que ocorre tanto na oferta quanto na identidade assumida pelos cursos focados em uma formação geral para acesso ao nível superior. Como muitos desses alunos não pretendem cursar essa modalidade de ensino, acabam desistindo do ensino médio, por considerá-lo desnecessário. A referida modalidade precisa, como argumenta Pacheco (2012, p. 74), superar a dualidade estrutural entre "[...] cultura geral e cultura técnica ou formação instrumental (para os filhos da classe operária) versus formação acadêmica (para os filhos das classes média - alta e alta)". Entende esse autor que o ensino médio de nível técnico seria uma opção que inclui a formação profissional para esses jovens:

É nesse contexto que a educação profissional técnica de nível médio - ao habilitar para o exercício de profissões técnicas - pode explicitar o significado da formação no ensino médio, como última etapa da educação básica. Em especial na forma integrada, a educação profissional técnica de nível médio (PACHECO, 2012, p.75).

O ensino técnico de nível médio é uma opção para os jovens possuírem, já no ensino médio, uma qualificação profissional que contribua para sua inserção no mundo do trabalho e seu desenvolvimento pessoal e profissional. Essa demanda por formação profissional técnica no país vem suscitando reflexões nos últimos anos e, consequentemente, ampliando a oferta de vagas nos cursos técnicos de nível médio em todos os ramos de atividades não só nas esferas públicas como nas particulares. A expansão da oferta de vagas nos cursos técnicos de nível médio é grande, ocasionando a ampliação das escolas técnicas consideravelmente. No caso da Rede Federal, por exemplo, a criação de novas escolas aumentou mais de $150 \%$, passando de 140 unidades em 2002 para 354 em 2010 (BRASIL, 2013).

Toda essa expansão gera reflexões e impulsionou a realização deste estudo buscando compreender um pouco da historicidade deste nível de ensino, abordando a educação profissional ou educação para o trabalho situando a origem e os avanços do ensino técnico profissional de nível médio.

\section{Educação Profissional}

A atual Lei de Diretrizes e Bases da Educação Nacional $n^{\circ}$ 9394, de 20 de dezembro de 1996, artigo 39, estabelece: "a educação profissional e tecnológica, no cumprimento dos objetivos da educação nacional, integra-se aos diferentes níveis e modalidades de educação e às dimensões do trabalho, da ciência e da tecnologia" (BRASIL, 1996).

Destacamos a dificuldade encontrada para levantar, ainda que sucintamente, aspectos históricos da educação profissional. Tal fato encontra uma explicação em Manfredi (2002) e Cunha (2000), os quais revelam que as pesquisas sobre a educação escolar estão mais direcionadas ao ensino superior ou ao ensino médio do que ao ensino profissional, demonstrando que os pesquisadores se preocupam muito mais com o ensino das elites e com o trabalho intelectual. Essa questão também advém da historicidade da escola, como afirma Manfredi (2002, p. 51):

Se, hoje, o imaginário social entende a escola como uma instituição que tem por função preparar os jovens para o ingresso no mercado de trabalho, historicamente, a constituição da escola não esteve vinculada à formação para o trabalho. Institucionalmente, ela foi criada para preparar grupos seletos de pessoas para o exercício do comando, do poder e da direção social.

Abordar a história da educação para o trabalho ou a história da educação profissional, sendo esta última expressão a mencionada pela maioria dos autores consultados, significa considerar práticas educativas para o trabalho além do espaço escolar, vivenciadas em outros espaços sociais, como argumenta Manfredi (2002, p. 54) ao caracterizar a educação no e para o trabalho como um:

[...] processo complexo de socialização e aculturação de jovens e adultos nos espaços de trabalho, entrecruzando-se com as aprendizagens realizadas em outros espaços socioculturais: bairro, escola, 
família, sindicato, partido, movimentos sociais e políticos, além de diferentes momentos da vida de cada sujeito trabalhador. Trata-se de processos de aprendizagem multifacetados, mediados por relações de historicidade entre sujeitos, contextos e tempos.

São nesses outros espaços em que se inicia a educação para o trabalho no Brasil, dos quais mencionamos, por exemplo, as tribos indígenas existentes antes da colonização, em que se fundiam práticas educativas e preparo para o trabalho no diaa-dia das tribos, na convivência entre os pares, em que os mais velhos faziam e ensinavam os mais jovens que aprendiam observando e participando das atividades de pesca, de caça, colheitas, confecção de objetos, construções, etc. "Tratava-se, portanto de um processo de Educação Profissional que integrava (e ainda integra) 'saberes' e 'fazeres' mediante o exercício das múltiplas atividades da vida em comunidade" (MANFREDI, 2002, p.66, grifo da autora).

Depois da educação profissional desenvolvida em comunidade pelos indígenas, tivemos, com a chegada dos portugueses nos séculos XV e XVI, a era do Brasil Colônia, com uma economia voltada à agroexportação de riquezas naturais - madeira e minérios - e à agroindústria açucareira, predominando o serviço escravo, realizado por negros trazidos da África e pelos índios nativos. Segundo Cunha (2005, p. 32), no período de colonização, em que a economia se pautava nos engenhos - unidades de plantação da cana de açúcar e produção do açúcar - tantos os negros como os homens livres aprendiam os ofícios no próprio trabalho "[...] sem padrões ou regulações, sem atribuições de tarefas para os aprendizes". Esclarece o autor que esses aprendizes eram recrutados conforme capacidades técnicas e sociais, avaliados pela disposição para aprendizagem, não sendo necessariamente crianças ou jovens.

Com o aumento da produção, a geração de núcleos urbanos, a extração de minério em Minas Gerais e a demanda dos consumidores, ampliaramse as atividades de comércio. Impôs-se a necessidade da formação de artesãos e mecânicos para desempenharem os ofícios de sapateiro, ferreiro, pedreiro, alfaiate, enfermeiro, roupeiro, porteiro e outros ofícios variados com uma formação profissional mais específica, organizada naquela época pela Companhia de Jesus, nos colégios dos Jesuítas, que ofereciam essa educação em oficinas ministradas por irmãos oficiais, preferencialmente para crianças e adolescentes, encaminhados conforme suas possíveis aptidões (CUNHA, 2005; MANFREDI, 2002).

A inserção de mão de obra escrava, no período colonial, influenciou a classificação de nossa força de trabalho em ofícios para os escravos e ofícios para os homens livres. Estudos de Cunha (2000), Manfredi (2002) e Santos (2011) evidenciam que os ofícios de artesanato e manufatura que utilizavam força física ou as mãos eram rejeitados pelos homens livres, que queriam se diferenciar dos escravos, caracterizando os trabalhos mencionados como ofício dos escravos ou trabalho desqualificado. Tais denominações geravam preconceito em relação aos trabalhos manuais, porém centrado mais em quem fazia tais trabalhos, se escravos ou homens livres, do que na atividade em si, uma vez que os "homens livres" reservavam para si algumas atividades manuais.

De acordo com Santos (2011), o preconceito para com as atividades manuais contribuiu para a aprendizagem das profissões que, naquele contexto, era realizada pelas Corporações de Ofícios, as quais foram instituídas no período colonial e com rigorosas normas de funcionamento, que dificultavam ou até impediam o ingresso de escravos. Seguindo esse pensamento, Cunha (2005) e Manfredi (2002), caracterizaram essas corporações em irmandades embandeiradas ou em ofícios não embandeirados, variando de uma cidade para outra, visto que as câmaras municipais tinham autonomia para atribuição dos nomes. A discriminação quanto à frequência dos escravos estava prescrita nas normas das escolas. Relata Santos (2011, p. 206), ao mencionar uma norma da Irmandade de São José, Corporação de Ofício do Rio de Janeiro: "Todo irmão em que se notar raça de mulato, mouro ou judeu, será expulso sem remissão alguma. O mesmo se estenderá de suas mulheres tendo qualquer das sobreditas faltas".

Diante desses dados, fica clara a influência que a escravidão teve na construção da concepção de trabalho, configurando como ruim os trabalhos manuais apenas por serem realizados por escravos. A função da educação na época era justamente afirmar, pelas suas normas, práticas e exclusões, sempre a favor da elite. Essa concepção distorcida ideologicamente resultou em preconceito, até os dias atuais, em relação ao trabalho manual.

A economia no país no século XVIII estava voltada ao pacto colonial, amparado pelo modelo 
agroexportador imposto pelos portugueses, que apresentavam resistência aos estabelecimentos industriais. A discriminação, em relação a realizar os trabalhos de "escravos" ou os de "homens livres", não causou dano ao país quanto à falta de mão-de-obra industrial, uma vez que, de 1706 a 1766, indústrias de vários ramos de atividades foram fechadas e, posteriormente, proibidas com a expedição do Alvará de 05 de janeiro de 1785, que obrigava o fechamento de todas as fábricas, com exceção das de tecelagem de fazendas grossas de algodão, que confeccionavam o vestuário dos negros. Esse modelo econômico prejudicou o ensino de profissões, conforme revela Santos (2011, p. 207): "A destruição da estrutura industrial que se instalou no Brasil durante o século XVIII causou forte impacto no desenvolvimento do ensino de profissões, cuja maioria era absorvida pelo setor secundário da economia."

O processo industrial foi retomado em 1808 com a vinda de D. João VI e, consequentemente, tornou necessária a aprendizagem profissional para suprir mão-de-obra nas indústrias. Ante esta carência, D. João VI criou, em 1809, o Colégio das Fábricas, de caráter assistencial, que ensinava ofícios às crianças e aos jovens órfãos e abandonados encaminhados pelos juízes e pela Santa Casa de Misericórdia. Estes eram internados nos arsenais Militares e da Marinha, onde trabalhavam como artífices e, após alguns anos, ganhavam a liberdade para escolher onde trabalhar. De acordo com Santos (2011, p. 208), “[...] essa instituição serviu de referência para as unidades de ensino profissional que vieram a ser instaladas no Brasil".

Em 1824, com a promulgação da Constituição Política do Império, em 25 de março, as corporações de ofícios, conforme artigo 179, inciso XXV, foram abolidas, inclusive seus juízes, escrivães e mestres (BRASIL, 1824).

Com o objetivo de estruturar os graus de ensino no país, o Projeto de Lei sobre a instrução pública, apresentado em 1826, foi uma das primeiras ações voltadas à organização da aprendizagem de ofícios. A divisão dos graus e dos estabelecimentos se dava da seguinte maneira: Pedagogias - primeiro grau; Liceus - segundo grau; Ginásios - terceiro grau; Academias - ensino superior. Com sua aprovação em 1827, a Lei determinava que as meninas tivessem aprendizagem de costura e bordado e que os Liceus ensinassem aos alunos desenho necessário às artes e aos ofícios (SANTOS, 2011).

\section{Ensino técnico de nível médio: dos Liceus Industriais até as Escolas Técnicas da rede federal}

A organização de sociedades civis, na primeira metade do século XIX, impulsionadas pelo aumento da produção manufatureira, foi responsável pela criação dos primeiros Liceus que ofertavam a aprendizagem das artes e dos ofícios, inicialmente mantidos por doações e quotas dos sócios e, posteriormente, com recursos do poder público. $\mathrm{O}$ primeiro Liceu de Artes e Ofícios foi inaugurado no Rio de Janeiro em 1858. Consta em Santos (2011, p. 210) que "um dos principais objetivos do Liceu de Artes e Ofícios do Rio de Janeiro era o de propagar e desenvolver pela classe operária a instrução indispensável ao exercício racional da parte artística e técnica das artes e dos ofícios industriais".

Além da criação do Liceu na capital do país à época, foram criados por organização de sociedades civis Liceus nos seguintes centros urbanos: Salvador em 1872, Recife em 1880, São Paulo em 1882, Maceió em 1884 e Ouro Preto em 1886. Os cursos eram oferecidos apenas aos homens livres, com matérias divididas em grupos de ciências aplicadas e grupos de artes, e a quantidade de matérias nos cursos profissionais era equivalente à das matérias do grupo de arte, informa Manfredi (2002).

Apesar dessas iniciativas para a formação de ofícios, só após a proclamação da República em 1889, a economia do país começou a se voltar à produção industrial, influenciando medidas direcionadas à educação profissional. O MEC (BRASIL, 2012a, p. 2) considera 1906 como o ano de consolidação do ensino técnico-industrial no Brasil, por terem sido promovidas as seguintes ações:

Realização do "Congresso de Instrução" que apresentou ao Congresso Nacional um projeto de promoção do ensino prático industrial, agrícola e comercial, a ser mantido com o apoio conjunto do Governo da União e dos Estados. O projeto previa a criação de campos e oficinas escolares onde os alunos dos ginásios seriam habilitados, como aprendizes, no manuseio de instrumentos de trabalho.

A Comissão de Finanças do Senado aumentou a dotação orçamentária para os Estados instituírem escolas técnicas e profissionais elementares sendo criada, na 
Estrada de Ferro Central do Brasil, a Escola Prática de Aprendizes das Oficinas do Engenho de Dentro, no Rio de Janeiro. Declaração do Presidente da República, Afonso Pena, em seu discurso de posse, no dia 15 de novembro de 1906:

“A criação e multiplicação de institutos de ensino técnico e profissional muito podem contribuir também para o progresso das indústrias, proporcionando-lhes mestres $e$ operários instruídos e hábeis" (Grifo do autor).

Em 1909, o Presidente da República, Nilo Peçanha, considerado o fundador do ensino profissional no Brasil, baixou o Decreto 7566, de 23 de setembro de 1909, criando 19 Escolas de Aprendizes e Artífices, uma em cada capital de Estado, com exceção do Rio de Janeiro (Distrito Federal da época) e do Rio Grande do Sul, que tiveram suas escolas construídas em Campos e Porto Alegre respectivamente (SANTOS, 2011; MANFREDI, 2002). Estabelecia o Decreto que essas escolas seriam mantidas pelo Ministério da Agricultura, Comércio e Indústria e sua finalidade consistia em oferecer ensino profissional primário e gratuito à população, bem como formar operários e contramestres. Elucida Cunha (2000, p. 94) que as "[...] escolas de aprendizes artífices tinham prédios, currículos e metodologia didática próprios; alunos, condições de ingresso e destinação esperada dos egressos que as distinguiam das demais instituições de ensino elementar".

No artigo $6^{\circ}$ do referido Decreto, consta que as escolas só poderiam admitir alunos com idade entre 10 e 13 anos, sem "[...] doenças infectocontagiosas ou defeitos que o impossibilitassem a aprendizagem do ofício" e ainda dar preferência aos "desfavorecidos da fortuna". A comprovação da situação econômica era regida pelo parágrafo segundo do mesmo artigo: "A prova de ser o candidato destituído de recursos será feita por atestação de pessoas idôneas, a juízo do diretor, que poderá dispensá-la quando conhecer pessoalmente as condições do requerente à matricula" (BRASIL, 1909). Ou seja, o diretor escolhia seus alunos, conforme sua convicção, ficando a dúvida se realmente a escola era para alunos desafortunados.

Os artigos $2^{\circ}, 3^{\circ}$ e $8^{\circ}$ do Decreto 7566 , de 23 de setembro de 1909, caracterizavam o funcionamento dos cursos, dos quais os de oficinas deveriam ser ministrados com aulas práticas e conhecimentos técnicos, podendo cada instituição ter até cinco oficinas de trabalho manual ou mecânico com funcionamento das dez às dezesseis horas. As unidades tinham também que oferecer dois cursos noturnos: primário, obrigatório para quem não soubesse ler, escrever e contar; e o de desenho, obrigatório para os alunos que necessitassem dessa disciplina para o exercício do ofício que iriam aprender (BRASIL, 1909). Essa oferta obrigatória demonstra que, desde aquela época, já existia a preocupação com os alunos em defasagem escolar, talvez até mais específica, do que nos dias atuais.

A Revolução de 1930, voltada ao modelo econômico de industrialização em larga escala, que intensificou o processo de expansão industrial no Brasil, influenciou o estabelecimento de políticas na educação. A criação do Ministério da Educação e da Saúde, segundo Santos (2011, p. 216), ocasionou uma reestruturação no sistema educacional brasileiro, "[...] notadamente no âmbito do ensino profissional que, ao instituir a Inspetoria do Ensino Profissional Técnico, ampliou os espaços de consolidação da estrutura do ensino profissional no Brasil". O novo Ministério da Educação e da Saúde, cujo primeiro ministro foi Francisco Campos, passou a supervisionar as Escolas de Aprendizes e Artífices pela Inspetoria supramencionada e, de acordo com MEC (BRASIL, 2012a), em 1934, a Inspetoria passou a ser Superintendência do Ensino Profissional, caracterizando um período de expansão desta modalidade de ensino.

Com a promulgação da Constituição brasileira de 1937, temos a primeira lei a tratar especificamente de ensino técnico, profissional e industrial, apesar de ainda caracterizar o ensino profissional como educação aos "pobres". Destacamos, em seu artigo 129:

$O$ ensino pré-vocacional e profissional destinado às classes menos favorecidas é, em matéria de educação, o primeiro dever do Estado. Cumpre-lhe dar execução a esse dever, fundando institutos de ensino profissional e subsidiando os de iniciativa dos Estados, dos Municípios e dos indivíduos ou associações particulares $e$ profissionais.

É dever das indústrias e dos sindicatos econômicos criar, na esfera de sua especialidade, escolas de aprendizes, destinadas aos filhos de seus operários ou de seus associados. A lei regulará o cumprimento desse dever e os poderes que 
caberão ao Estado sobre essas escolas, bem como os auxílios, facilidades e subsídios a lhes serem concedidos pelo poder público (BRASIL, 1937a, grifo nosso).

Com a Lei número 378, de 13 de janeiro de 1937, as Escolas de Aprendizes e Artífices receberam a denominação de Liceus profissionais, com oferta de ensino profissional a todos os ramos e graus (BRASIL, 1937b). E em 1942, pelo Decreto 4127, de 25 de fevereiro, passaram a ser denominadas de Escolas Industriais e Técnicas, oferecendo formação profissional em nível equivalente ao ensino médio ou secundário (BRASIL, 1942b), podendo os alunos formados nos cursos técnicos ingressarem "no ensino superior em área equivalente à da sua formação" (BRASIL, 2012a, p. 4).

Em 1942, houve a promulgação de várias leis voltadas à reformulação do ensino primário e médio, inclusive considerando o ensino profissional de nível médio, que corresponde hoje ao denominado ensino técnico de nível médio. Essas reformas ocorreram por iniciativa do Ministro da Educação e da Saúde no Governo Getúlio Vargas, Gustavo Capanema e marcaram a história da educação profissional, estruturando todo o sistema oficial do ensino técnico profissional. As leis denominadas de Leis Orgânicas do Ensino foram decretadas a partir de 1942, conforme relata Romanelli (2010, p. 158):

a) Em 30 de janeiro de 1942, o decreto-lei 4073 organizava o ensino industrial (Lei Orgânica do Ensino Industrial);

b) em 28 de dezembro de 1943 saía a Lei Orgânica do Ensino Comercial, pelo decreto-lei 6.141;

c) e, em 20 de agosto de 1946, findo, portanto, o Estado Novo, saía o decreto-lei 9.613, chamado Lei Orgânica do Ensino Agrícola.

Afirma a autora que esses três decretos organizaram o ensino técnico profissional nas três áreas da economia - setores industriais, comerciais e agrícolas -, em dois ciclos, um fundamental geral de quatro anos e um técnico de três a quatro anos.

$\mathrm{O}$ ensino comercial era composto por um curso básico no primeiro ciclo e vários cursos técnicos no segundo, como, por exemplo: comércio, propaganda, administração, contabilidade, estatística e secretariado (BRASIL, 1943). Já o ensino agrícola tinha, no primeiro ciclo, o curso básico agrícola de quatro anos e o de mestria de dois anos e, no segundo ciclo, os cursos técnicos: agricultura, horticultura, zootécnica, prática veterinária, indústrias agrícolas, laticínios e mecânica agrícola. Nesse ramo do ensino, havia a oferta de cursos pedagógicos de um ano, o de didática do ensino agrícola e o de administração de ensino agrícola (BRASIL, 1946a). No ensino industrial, regulamentado pelo Decreto 4.073, os dois ciclos ministrados eram assim compostos: o primeiro por ordens de ensino industrial básico, de ensino de mestria, de ensino artesanal e de ensino da aprendizagem; o segundo ciclo compreendia as ordens do ensino técnico e do ensino pedagógico, no qual ofereciam curso de formação de professores de um ano. As ordens citadas eram desdobradas em seções e estas em cursos (BRASIL, 1942c).

Acrescentamos que, nessa Lei Orgânica, o governo dividia sua responsabilidade de formação profissional com as indústrias, constituindo como obrigação dos empregadores o ensino dos ofícios, cuja execução exigia formação profissional, e a obrigação de manter aprendizes a seu serviço. Segundo Romanelli (2010, p. 159), "Este é o aspecto de indiscutível valor da história do ensino profissional, pois revela uma preocupação do governo em engajar as indústrias na qualificação de seu pessoal, além de obrigá-las a colaborar com a sociedade na educação de seus membros".

Em 1942, pelo Decreto 4.048, de 22 de janeiro de 1942, o governo de Getúlio Vargas criou o Serviço Nacional de Aprendizagem Industrial SENAI - em convênio com o setor industrial, representado pela Confederação Nacional da Indústria $(\mathrm{CNI})$, mantido pelas indústrias, que eram obrigadas a uma contribuição mensal destinada às escolas de aprendizagem (BRASIL, 1942a). Elucida Santos (2011) que o objetivo da criação do SENAI era oferecer cursos profissionais de curta duração, para que os aprendizes menores se inserissem nas indústrias, e cursos de formação continuada, para trabalhadores. Além do SENAI, o governo criou, com estrutura semelhante, pelo Decreto-lei 8621, de 10 de janeiro de 1946, o Serviço Nacional de Aprendizagem Comercial - SENAC, destinado ao setor do Comércio dirigido e organizado pela Confederação Nacional do Comércio (BRASIL, 1946b).

Para Romanelli (2010) a criação do SENAI e do SENAC, denominados pela autora de sistemas de ensino paralelo ao oficial de educação profissional, ocorreu em virtude de o sistema 
educacional do país não possuir infraestrutura necessária à implantação do ensino profissional em quantidade suficiente para atender às demandas do mercado e por não ser esse ramo de ensino de interesse das classes médias, atuais demandantes pelo aumento da oferta em educação. Evidencia a autora que as escolas do sistema paralelo do ensino profissional tiveram maior número de matrículas do que as do sistema oficial, em virtude daquelas oferecerem mais cursos de curta duração, voltados aos trabalhadores ou aos jovens que precisavam trabalhar mais cedo, além de oferecer pagamento aos alunos que ali estudavam, enquanto que as escolas do sistema oficial, por sua vez, mesmo tendo como objetivo nas suas Leis Orgânicas a oferta de cursos rápidos, ofereciam mais cursos técnicos e de formação semelhantes ao ensino secundário, exigindo dos estudantes destes cursos maior tempo dedicado aos estudos.

Como o ensino profissional oficial tinha uma matrícula sensivelmente inferior à do sistema paralelo, tornou-se evidente que o sistema oficial de ensino, em seus ramos secundário e superior, continuou sendo o sistema das elites, ou, ao menos, das classes médias e altas, enquanto o sistema "paralelo" de ensino profissional, ao lado das escolas primárias, passou a ser mais acentuadamente o sistema educacional das camadas populares. Aí está o significado da criação e da manutenção do sistema paralelo do ensino, ao lado de um sistema oficial [...] (ROMANELLI, 2010. p. 174).

Além do SENAI e SENAC, outras instituições parecidas foram criadas formando hoje o chamado "Sistema S", que são instituições que realizam serviços nacionais de aprendizagem e serviços sociais, mantidas por contribuições parafiscais das empresas privadas. Além delas, foram criadas, com o decorrer do tempo, como ofertantes da educação profissional, várias instituições, tanto no setor público como no setor privado e em vários espaços sociais, além da escola, como sindicatos, empresas, associações de bairros e outros que contribuíram e ainda contribuem para formação profissional em nosso país. Como nossa pesquisa foi realizada em uma instituição de ensino técnico da rede federal, o estudo histórico focou na legislação da educação profissional e na evolução ou modificação que as escolas técnicas da rede federal sofreram desde as Leis Orgânicas criadas por Gustavo Capanema mencionadas anteriormente.

Depois da promulgação das referidas leis no ensino industrial, comercial e agrícola, vários debates e medidas legais ocorreram em torno delas. Dentre elas, citamos a Lei número 1821, de doze de março de 1953, que regulamentava a lei de equivalência entre os cursos básicos e técnicos de ensino industrial, agrícola e comercial e os cursos ginasial e secundário. Esta estabelecia a possibilidade de os alunos de tais cursos realizarem matrículas no ciclo colegial e nos cursos superiores, desde que atendessem a algumas exigências, como a realização de exames das disciplinas dos cursos ginasial ou secundário que não foram cursadas durante a educação profissional (BRASIL, 1953).

Outra mudança importante foi a descentralização das Escolas Técnicas Federais, regulamentadas pelo Decreto número 47.038, de 16 de outubro de 1959, que instituiu a autonomia didática, financeira, administrativa e técnica, atribuindo às escolas uma personalidade jurídica própria, ficando a cargo de a Diretoria do Ensino Industrial propor a distribuição dos fundos orçamentários e a instituição das diretrizes gerais dos currículos e materiais pedagógicos (RODRIGUES, 2002; BRASIL, 1959).

Em 1961, foi promulgada a primeira Lei de Diretrizes e Bases da Educação Nacional, a de número 4024, de 20 de dezembro, que dedica um capítulo à educação profissional de nível técnico (BRASIL, 1961). Uma das mudanças significativas que proporcionou foi regulamentar novamente a lei de equivalência, que passou a ser plena em todos os cursos do nível médio, inclusive os técnicos, permitindo o acesso ao ensino superior sem o aluno ter que realizar exames ou avaliações. Segundo Mendes (2005) a LDB de 1961 possuía lacunas a serem interpretadas e regulamentadas sobre o ensino profissional, gerando a criação de várias portarias regulamentadoras, em 1962, dentre elas: a DEI 26 $\mathrm{BR}$, de 07 de março, que estabeleceu como obrigatório o estágio; a DEI 22, de 27 de março, que especificava as disciplinas obrigatórias de cada especialidade do curso técnico industrial e a Portaria Ministerial número 163, de 4 de julho, que permitia o funcionamento de cursos técnicos em três anos para quem houvesse concluído o secundário, sendo um deles de estágio. Reconhece o autor que a educação profissional se modificou de acordo com as mudanças econômicas, sociais e políticas ocorridas ao longo da história, voltada mais a interesses capitalistas e ao ensino das elites. 
Na era da Ditadura Militar, houve uma grande mudança na educação profissional, com a promulgação da Lei número 5692, de 11 de agosto de 1971, ao estabelecer a profissionalização universal e compulsória no ensino médio ou ensino de segundo grau (BRASIL, 1971). De acordo com Manfredi (2002), essa profissionalização ocorreu quando o país tinha como objetivo participar da economia internacional, delegando à educação a preparação de recursos humanos para o mercado de trabalho. A interpretação de Santos (2011, p. 219) é que "os efeitos dessa reforma sobre o ensino médio foram o de não produzir nem a profissionalização nem o ensino propedêutico, tendo em vista o fracasso da politica educacional imposta pela política aplicada pelo regime militar". Acrescenta o autor que, apesar de a Lei estabelecer uma profissionalização para todos, independente de classe social, isso não ocorria para as classes menos favorecidas, de trabalhadores instrumentais, que nem sequer chegavam ao ensino secundário, mantendo uma dualidade entre os ramos de ensino, privilegiando a classe das elites. Em 1982, pela Lei número 7044, de 18 de outubro, eliminou-se o caráter compulsório da profissionalização no ensino médio (BRASIL, 1982).

Quanto às Escolas Técnicas Federais, no decorrer dessas mudanças, passaram de escolas destinadas aos pobres e desvalidos, quando Escolas de Aprendizes e Artífices, para escolas de alto prestígio junto ao empresariado, visto que grande parcela dos técnicos, formados entre os anos de 1960 e 1970, era recrutada por grandes empresas. Todo esse prestígio aumentou o número de matrículas, passando, em algumas escolas maiores que tinham entre 100 a 400 alunos, para 4.000 até 6.000 em um período de 10 anos (SANTOS, 2011).

Com o aumento de matrículas, as escolas mencionadas implantaram novos cursos técnicos e algumas iniciaram a oferta de engenharias e cursos tecnológicos, sendo transformadas em Centros Federais de Educação Tecnológica - CEFETs, gradativamente e mediante decretos específicos. Essas mudanças iniciaram-se em 1978, em que tivemos a transformação de três unidades (Paraná, Minas Gerais e Rio de Janeiro) e continuaram até 1999 (BRASIL, 2012a).

Nos anos 80 e 90 do século XX, os debates se deram em torno das mudanças educacionais, dentre elas a reestruturação da educação profissional. Esses resultaram na promulgação da atual LDB - Lei de Diretrizes e Bases da Educação, número 9.394, de 20 de dezembro de 1996, que revogou a Lei número 5692, de 11 de agosto de 1971, e incluiu, como etapa da educação básica, o ensino médio, com duração mínima de três anos, tendo como finalidade, segundo seu artigo 35 :

I - a consolidação e o aprofundamento dos conhecimentos adquiridos no ensino fundamental, possibilitando o prosseguimento de estudos;

II - a preparação básica para o trabalho $e$ a cidadania do educando, para continuar aprendendo, de modo a ser capaz de se adaptar com flexibilidade a novas condições de ocupação ou aperfeiçoamento posteriores;

III - o aprimoramento do educando como pessoa humana, incluindo a formação ética $e$ o desenvolvimento da autonomia intelectual e do pensamento crítico;

IV - a compreensão dos fundamentos científico-tecnológicos dos processos produtivos, relacionando a teoria com a prática, no ensino de cada disciplina (BRASIL, 1996, grifo nosso).

Portanto, a Lei número 9394/96 determina que o ensino médio seja a etapa final da educação básica, possibilitando o ingresso ao ensino superior somente aos que o concluírem. Conforme Manfredi (2002, p. 119) essa reestruturação:

[...] acabou por configurar um desenho de ensino médio que separa a formação acadêmica da Educação Profissional, aproximando-se muito mais dos interesses imediatos dos empresários e das recomendações dos órgãos internacionais do que das perspectivas democratizantes inerentes aos projetos defendidos pelas entidades da sociedade civil.

Quanto aos cursos técnicos de nível médio, podem ser cursados concomitantemente ou sequencialmente ao ensino médio e segundo art. $5^{\circ}$ da resolução do CNE - Conselho Nacional de Educação n 06 de 20 de setembro de 2012, “[...] têm por finalidade proporcionar ao estudante conhecimentos, saberes e competências profissionais necessários ao exercício profissional e da cidadania, com base nos fundamentos científicotecnológicos, socio-históricos e culturais." (BRASIL, 2012c)

Para regulamentar a educação profissional, 
após a Lei número 9394/96, o governo criou o Decreto número 2.208, de 17 de abril de 1997, e a educação profissional fica com a seguinte estrutura: cursos de níveis básicos, oferecidos a trabalhadores para qualificação independente de escolaridade prévia; cursos técnicos de nível médio, para habilitação de alunos egressos do ensino médio e cursos tecnológicos, com habilitação em nível superior (BRASIL, 1997).

O ensino técnico, campo de pesquisa de nossos estudos, após a promulgação desses dois dispositivos legais, passa a ser complementar ao ensino médio, uma vez que, independentemente de ser cursado de modo concomitante ou subsequente, necessita da conclusão daquele para certificação, rompendo com a lei de equivalência, e "retoma", se é que um dia ela deixou de existir, a dualidade: ensino básico para a elite acessar o ensino superior versus ensino profissional para classe média.

Discordando da problemática sobre a dualidade e a exclusão, o MEC (BRASIL, 2012a, p. 5) afirma que a Lei 9394/96, por conceder à educação profissional um capítulo separado da educação básica, supera:

[...] enfoques de assistencialismo $e$ de preconceito social contido nas primeiras legislações de educação profissional do país, fazendo uma intervenção social crítica e qualificada para tornar-se um mecanismo para favorecer a inclusão social $e$ democratização dos bens sociais de uma sociedade.

Baseado nessa política de democratização, o governo federal, pelo mencionado Decreto número 2.208, de 17 de abril de 1997, criou o programa de expansão da educação profissional. Na Rede Federal, esta expansão construiu mais escolas técnicas federais ou CEFETs, totalizando 140 unidades, até 2002. Em 2005, instituiu-se um plano de expansão somente da Rede Federal, amparado pela Lei 11.195 , de 2005, para construção de mais 64 unidades e, em 2007, o governo lançou a segunda fase de expansão, com mais 150 escolas, totalizando 354 unidades em todo o país. Existe previsão de implantação de mais 208 novas escolas, totalizando 562 unidades (BRASIL, 2014).

Diante de todas essas mudanças e expansões, os CEFETs e Escolas Técnicas Federais também sofreram modificações. Com a Lei número 11892, de 29 de dezembro de 2008, são criados os Institutos Federais de Educação Ciência e
Tecnologia (IF) em substituição aos Centros Federais de Educação Tecnológica (CEFET) e escolas técnicas (BRASIL, 2008a).

Com nova estrutura e autonomia, os Institutos Federais têm como foco, segundo Silva (2009, p.8):

[...] a promoção da justiça social, da equidade, do desenvolvimento sustentável com vistas a inclusão social, bem como a busca de soluções técnicas e geração de novas tecnologias. Estas instituições devem responder, de forma ágil e eficaz, às demandas crescentes por formação profissional, por difusão de conhecimentos científicos e de suporte aos arranjos produtivos locais (Grifo nosso).

Um dos objetivos da educação profissional é a formação para inserção no mundo do trabalho, de modo que este contribua tanto para o desenvolvimento pessoal e profissional do cidadão, como para o desenvolvimento da sociedade. Porém, na ideologia atual, é comum o desenvolvimento estar ligado ao pleno atendimento às demandas do mercado capitalista. Priorizando, com frequência, atender mais a essas demandas, do que a formação profissional com equidade, o governo vem investindo massivamente na expansão da educação profissional, sobretudo no ensino técnico, em que a preocupação é ampliar a oferta, democratizar o acesso e atender ao mercado, de forma "ágil e eficaz". Tal política evidencia que, apesar de todas as mudanças ocorridas historicamente na educação profissional, uma de suas características ainda é mantida: o controle do mercado e do capitalismo sobre as politicas para educação profissional. A esse respeito, Gimeno Sacristán (1999, p. 246) alerta que:

O mercado opõe-se à educação pela lógica interna de ambos os processos: enquanto a finalidade do mercado é a obtenção dos máximos benefícios econômicos possíveis, a educação tem como função fazer avançar e disseminar o conhecimento ao maior número de pessoas possível. [...]. $O$ mercado vende e compra coisas, a educação procura fazer com que todos, de forma autônoma, apropriem-se daquilo que os beneficia e cuja duração será maior quanto maior for sua apropriação. 
Buscando uma comparação do Brasil com alguns países quanto às matrículas de alunos no ensino técnico de nível médio, apresentamos os seguintes dados:

Porcentagem de alunos em cursos profissionais e técnicos de nível médio, países selecionados (ISCED 3)

\begin{tabular}{l|l}
\hline Alemanha & 51.5 \\
\hline Argentina & 20.6 \\
\hline Brasil & 14.2 \\
\hline Chile & 36.6 \\
\hline Colômbia & 27.5 \\
\hline França & 44.3 \\
\hline Espanha & 44.5 \\
\hline Finlândia & 56.2 \\
\hline México & 9.5 \\
\hline Portugal & 40.6
\end{tabular}

Fonte: Tabulação de Dados do Instituto de Estatísticas da UNESCO- 2012 apud

SCHWARTZMAN; CASTRO (2013)

Portanto, comparando o Brasil com os demais países, o quantitativo de alunos matriculados nos cursos de ensino técnico de nível médio ainda é bem inferior estando, dos países mencionados, acima apenas do México. Salientamos que estes dados são de 2012 e desde lá o Brasil vem investindo massivamente na ampliação desse número.

\section{Considerações Finais}

Após este breve resgate histórico evidenciamos momentos de alto prestígio $\mathrm{e}$ momentos de esquecimento desse ramo de ensino, sempre baseados no momento político em que o país se encontra, ora o considerando suficiente para ingresso no ensino superior, ora considerando apenas complementar ao atual ensino médio propedêutico que deveria formar os alunos para serem cidadãos críticos, capazes de atuar no mundo do trabalho com autonomia. Portanto a educação profissional técnica em nosso país sempre sofreu influências de políticas públicas descontinuadas, em que a necessidade de mão de obra para atender as demandas do mercado influencia a expansão ou não de escolas para esta formação técnica. Confunde-se a função social da escola de formar cidadãos críticos para transformar a sociedade com a obrigatoriedade de atender as exigências econômicas capitalistas.

Apesar de não concordamos com os motivos que impulsionam essa expansão, ressaltamos, neste trabalho, a necessidade sim de formar jovens para o mundo do trabalho, de modo que estes consigam melhores empregos e oportunidades e consigam atuar criticamente na sociedade, possibilitando inclusive sua reconstrução. Portanto, trata-se de uma educação profissional que possibilite a formação técnica, porém, garanta também a função social da escola, possibilitando aos egressos desses cursos atuarem no mundo do trabalho com autonomia, criticidade e visando a transformação da sociedade em que atua.

$\mathrm{O}$ II fórum mundial de educação profissional e tecnológica, realizado em 2012, traz em um dos itens integrantes da carta de princípios, como sua agenda, garantir educação profissional e tecnológica voltada para jovens e adultos, trabalhadores e trabalhadoras, como política pública que possibilite a inclusão crítica de todas as pessoas nos processos de construção democrática da sociedade. Trata-se de uma preocupação mundial a formação de profissionais qualificados para atuar em uma sociedade democrática, podendo considerar que a preocupação com estes cursos volta a estar em situação privilegiada. Em consonância com esta preocupação, atualmente o Brasil vem construindo políticas públicas para ampliar a oferta de cursos técnicos de nível médio, com uma expansão acelerada dos Institutos Federais que oferecem este ensino e que nos últimos anos tiveram uma expansão considerável passando de 140 unidades em 2002 para 354 atualmente, tendo previsão de mais unidades para 2014 chegando a quase dobrar a quantidade atual. Outra política pública nesse sentido é o PRONATEC - Programa Nacional de Acesso ao Ensino Técnico e Emprego que oferece verba, inclusive, para instituições privadas ofertarem esses cursos. Portanto, o país vem, nos últimos anos, ampliando consideravelmente sua atuação nesse ramo de ensino. 
Ressaltamos que mudanças ainda precisam ser feitas, uma delas é referente ao acesso no ensino superior em que o aluno precisa ter concluído o ensino médio, não bastando apenas um curso técnico de nível médio. Assim, o ensino técnico mais uma vez perde um pouco sua identidade e os alunos acabam optando em cursar apenas a modalidade que lhe permita a continuidade dos estudos, elitizando mais uma vez a educação de nível médio geral.

Toda expansão do ensino técnico de nível médio vem sendo declarada pelo governo como intenção de democratizar o acesso, aumentando o número de vagas, porém não temos nos documentos oficiais políticas que apontem como esta formação está sendo ofertada quanto à qualidade e a real contribuição desta formação na vida dos alunos egressos destes cursos. Esta é a inquietação que fica: Como esta expansão está sendo feita, como está sendo garantida, de fato, a "justiça social" e a "equidade" visando à inclusão social? Como estão sendo contratados os professores destes cursos, com que formação? O presente estudo tratou apenas da parte histórica deste ensino, buscando retratar sua evolução ao longo dos anos, porém salientamos a importância de pesquisas que abordem aspectos qualitativos desta expansão, tratando questões como formação de professores e perfil dos alunos egressos.

\section{Referências}

\section{BRASIL. Constituição Política do Império do}

Brasil (1824). Disponível em:
<http://www.monarquia.org.br/PDFs/CONSTITUIC AODOIMPERIO.pdf >. Acesso em: 25 mar. 2013.

BRASIL. Constituição Federal Brasileira, de 10 de novembro de 1937. Constituição dos Estados Unidos do Brasil de 1937. Diário Oficial da União, Rio de Janeiro, 10 nov. 1937a.

BRASIL. Decreto-Lei $n^{\circ} 9.613$, de 20 de agosto de 1946. Lei Orgânica do Ensino agrícola. Diário Oficial da União, Rio de Janeiro, Seção 1, p. 12019, 23 ago. 1946a.

BRASIL. Decreto $\mathrm{n}^{\mathrm{o}} 4.048$ de 22 de Janeiro de 1942. Cria o Serviço Nacional de Aprendizagem dos Industriários (SENAI). Diário Oficial da União, Rio de Janeiro, Seção 1, p. 1231, 24 jan. 1942a.

BRASIL. Decreto n 2.208 de 17 de abril de 1997. Regulamenta o par. 2 do art. 36 e os arts. 39 a 42 da lei 9394, de 20 de dezembro de 1996, que estabelece as diretrizes e bases da educação nacional. Diário Oficial da União, Brasília, p. 7760, 18 abr. 1997.

BRASIL. Decreto $n^{\circ} 4.127$ de 25 de fevereiro de 1942. Estabelece as bases de organização da rede federal de estabelecimentos de ensino industrial. Diário Oficial da União, Rio de Janeiro, Seção 1, p. 2957, 27 fev. 1942 b.

BRASIL. Decreto $n^{\circ} 47.038$ de 16 de outubro de 1959. Aprova o Regulamento do Ensino Industrial. Diário Oficial da União, Rio de Janeiro, Seção 1, p. 22593, 23 out. 1959.

BRASIL. Decreto $\mathrm{n}^{\circ} 7.566$ de 23 de setembro de 1909. Crêa nas capitaes dos Estados da Republica Escolas de Aprendizes Artifices, para o ensino profissional primário e gratuito. Coleção de Leis do Brasil, v. 2, coluna 1. p. 445, 31 dez. 1909.

BRASIL. Decreto-Lei $n^{\circ} 4.073$, de 30 de janeiro de 1942. Lei orgânica do ensino industrial. Diário Oficial da União, Rio de Janeiro, seção 1, p. 1997, 9 fev. 1942c.

BRASIL. Decreto-Lei ${ }^{\circ} 6.141$ de 28 de dezembro de 1943. Lei Orgânica do Ensino Comercial. Diário Oficial da União, Rio de Janeiro, Seção 1, p. 19217, 31 dez. 1943.

BRASIL. Decreto-Lei $n^{\circ}$ 8.621, de 10 de janeiro de 1946. Dispõe sobre a criação do Serviço Nacional de Aprendizagem Comercial e dá outras providências. Diário Oficial da União, Rio de Janeiro, Seção 1, p. 541, 12 jan. 1946b.

BRASIL. Lei $n^{\circ} 11892$, de 29 de dezembro de 2008. Institui a Rede Federal de Educação Profissional, Científica e Tecnológica, cria os Institutos Federais de Educação, Ciência e Tecnologia, e dá outras providências. Diário Oficial da União, Brasília, p. 1, 30 dez. 2008a.

BRASIL. Lei n ${ }^{\circ}$ 9394, de 20 de dezembro de 1996. Estabelece as diretrizes e bases da educação nacional. Diário Oficial da União, Brasília, p. 27833, 23 dez. 1996. 
BRASIL. Lei no 4.024, de 20 de dezembro de 1961. Fixa as diretrizes e bases da Educação Nacional. Diário Oficial da União, Rio de Janeiro, p. 11429, 27 dez. 1961.

BRASIL. Lei $\mathrm{n}^{\circ} 11.741$, de 16 de Julho de 2008 . Altera dispositivos da lei n. ${ }^{\circ} 9.394$, de 20 de dezembro de 1996, que estabelece as diretrizes e bases da educação nacional, para redimensionar, institucionalizar e integrar as ações da educação profissional técnica de nível médio, da educação de jovens e adultos e da educação profissional e tecnológica. Diário Oficial da União, Brasília, p. 5, 17 jul. 2008 b.

BRASIL. Lei $\mathrm{n}^{\circ} 1.821$ de 12 de março de 1953. Dispõe sobre o regime de equivalência entre diversos cursos de graus médio para efeito de matrícula no ciclo colegial e nos cursos superiores. Diário Oficial da União, Rio de Janeiro, Seção 1, p. 4505, 16 mar. 1953.

BRASIL. Lei $n^{\circ} 378$ de 13 de Janeiro de 1937. Dá nova organização ao ministério da educação e saúde pública. Diário Oficial da União, Rio de Janeiro, p. 1210, 15 jan. $1937 b$.

BRASIL. Lei $\mathrm{n}^{\circ}$ 5.692, de 11 de agosto de 1971. Fixa diretrizes e bases para o ensino de 1. e 2 graus, e da outras providencias. Diário Oficial da União, Brasília, Seção 1, p. 6377, 12 ago. 1971.

BRASIL. Lei $\mathrm{n}^{\circ} 7.044$ de 18 de outubro de 1982. Altera dispositivos da Lei $\mathrm{n}^{\circ} 5.692$, de 11 de agosto de 1971, referentes a profissionalização do ensino de $2^{\circ}$ grau. Diário Oficial da União, Brasília, Seção 1, p. 19539, 19 out. 1982.

BRASIL. Ministério da Educação. Centenário da Rede Federal de Educação Profissional e Tecnológica. Disponível em:< http://portal.mec.gov.br/ setec/arquivos/centenario/historico_educacao_profis sional.pdf > Acesso em: 12 jun. 2012a.

BRASIL. Ministério da Educação. Expansão da rede federal. Disponível em: $<$ http://redefederal.mec.gov.br/index.php?option=co $\mathrm{m} \_$content $\&$ view $=$ article $\& \mathrm{id}=52 \&$ Itemid $=2>$.

Acesso em: 15 jan. 2013.

BRASIL. Ministério da Educação. Expansão da rede federal. Disponível em: < http://redefederal.mec.gov.br/expansao-da-redefederal >. Acesso em: 15 ago. 2014.

BRASIL. Ministério da Educação. Instituto Nacional de Estudos e Pesquisas Educacionais. Sinopse estatística da educação básica. 2011. Disponível em: <http://portal.inep.gov.br/basicacenso-escolar-sinopse-sinopse>. Acesso em: 6 set. 2012b.

BRASIL. Ministério da Educação. Resolução CNE/CEB n ${ }^{\circ} 6$ de 20 de setembro de 2012. Diário Oficial da União, Brasília, Seção 1, p. 22, 21 set. 2012c.

CUNHA. L. A. O ensino de ofícios artesanais e manufatureiros no Brasil escravocrata. 2. ed. São Paulo: Ed. UNESP, 2005. p. 27-57.

CUNHA. L. A. O ensino industrial-manufatureiro no Brasil. Revista Brasileira de Educação, São Paulo, n. 14, p. 89-107, maio/ago. 2000.

GIMENO SACRISTÁN, J. Poderes instáveis em educação. Tradução de Beatriz Affonso Neves. Porto Alegre: Artes Médicas Sul, 1999.

MANFREDI, S. M. Educação profissional no Brasil. São Paulo: Cortez, 2002.

MENDES, L. O. Políticas públicas e a pedagogia das competências na educação profissional: a trajetória do ensino profissionalizante de nível técnico no Brasil e no Estado de São Paulo. 2005. 278 f. Tese (Doutorado em Educação) Universidade Estadual de Campinas, Faculdade de Educação, Campinas, 2005.

PACHECO, E. (Org.). Perspectivas da educação profissional técnica de nível médio. São Paulo: Fundação Santillana Moderna, 2012.

RODRIGUES, J. Celso Suckow da Fonseca e a sua "História do ensino industrial no Brasil". Revista Brasileira de História da Educação, Campinas, n. 4, jul./dez. 2002. Disponível em: <http://www.rbhe.sbhe.org.br/index.php/ rbhe/article/download/246/253>. Acesso em: 12 jun. 2012.

ROMANELLI, O. O. História da educação no Brasil. 36. ed. Petrólolis: Vozes, 2010.

SANTOS, J. A. A trajetória da educação 
profissional. In: LOPES, E. M. T.; FARIA FILHO, L. M. (Org.). 500 anos de educação no Brasil. 5. ed. Belo Horizonte: Autêntica, 2011. p. 205-224.

SCHWARTZMAN, S; CASTRO, C. M. Ensino, formação profissional e a questão da mão de obra. Ensaio: avaliação e políticas públicas em Educação, Rio de Janeiro, v. 21, n. 80, p. 563-624, jul./set.
2013.

SEVERINO, A. J. Metodologia do trabalho científico. São Paulo: Cortez, 2000.

SILVA, R. J. C.(Org.). Institutos federais lei 11. 892, de 29/11/2008: comentários e reflexões. Natal: IFRN, 2009. p. 7-11.

\section{Sobre a autora:}

Aline Graciele Mendonça: Mestre em educação pela Universidade Estadual de Londrina (UEL). Possui graduação em Licenciatura Plena em Pedagogia e especialização/ pós graduação lato sensu: Produção de Texto na Escola. Atua como docente no Instituto Federal de Educação, Ciência e Tecnologia de São Paulo - Campus Birigui.

Recebido em 15/03/2014

Aprovado em 11/11/2014 